Jakub Ratajczak ${ }^{*}$, Piotr Łach ${ }^{*}$, Stanisław Szczerbiński², Przemysław Paciorek ${ }^{1}$, Joanna Karłowska-Pik ${ }^{3}$, Bartosz Ziemkiewicz ${ }^{3}$, Małgorzata Jasiewicz ${ }^{1}$, Aldona Kubica ${ }^{4}$

* Jakub Ratajczak and Piotr Łach are equal contributors

${ }^{1}$ Department of Cardiology and Internal Medicine, Nicolaus Copernicus University,

Collegium Medicum in Bydgoszcz, Poland

${ }^{2}$ Emergency Medical Center in Opole, Opole, Poland

${ }^{3}$ Department of Probability Theory and Stochastic Analysis, Nicolaus Copernicus

University, Torun, Poland

${ }^{4}$ Department of Health Promotion, Nicolaus Copernicus University, Collegium Medicum in

Bydgoszcz, Poland

\title{
Atmospheric conditions and the occurrence of out-of-hospital cardiac arrest in Poland - preliminary analysis of poorly understood phenomena
}

\author{
Corresponding author: \\ Malgorzata Jasiewicz \\ University Hospital No. 1 \\ Department of Cardiology \\ and Internal Medicine \\ M. Sklodowskiej-Curie 9 St. \\ 85-094 Bydgoszcz, Poland \\ E-mail: jasiewiczm@gmail.com
}

Medical Research Journal 2018; Volume 3, Number 3, 121-126 10.5603/MRJ.2018.a0019 Copyright (C) 2018 Via Medica ISSN 2451-2591

\begin{abstract}
Background: The aim of this study was to investigate numerous daily weather conditions and the incidence of out-of-hospital cardiac arrest (OHCA) in the moderate climate of Poland. The authors particularly wanted to examine yet poorly explored individual atmospheric parameters that may presumably influence the incidence of $\mathrm{OHCA}$.

Methods: The retrospective analysis of OHCA cases based on dispatch cards from Emergency Medical Centre in Opole, Poland covering 2 years (2006-2007). Total of 815 adults with presumed cardiac aetiology of OHCA was included.

Results: The mean age of the group was 69,2 \pm 14,2 years, with the majority of men (63\%). No statistically significant differences were found in the incidence of OHCA regarding analysed weather conditions. In the subgroup of men, the incidence of OHCA was higher on days with the atmospheric pressure increase between consecutive days ( $p=0.028$ ) with the highest prevalence on days with pressure increase less than $5 \mathrm{hPa}(\mathrm{p}=0.026)$. In a group of patients $\leq 65$ years old the incidence of OHCA was the highest on days with day-to-day pressure change between 0.1 and $4.9 \mathrm{hPa}(\mathrm{p}=0.025)$.

Conclusions: Among many weather parameters, only a few of them might be significant for the occurrence of OHCA in the moderate climate of Poland. In the population of men and patients $\leq 65$ years old the incidence of OHCA may be influenced by atmospheric pressure changes.

Key words: cardiac arrest, variability, temperature, atmospheric pressure, humidity, weather conditions
\end{abstract}

\section{Introduction}

Out-of-hospital cardiac arrest (OHCA) is a considerable health problem worldwide. Although the recent studies presented that the survival rate has improved [1-2] it is still low, ranging from $8 \%$ in the USA to $10,7 \%$ in Europe [3-4]. The majority of OHCA events (70-85\%) have a cardiac aetiology and there are well-established patient-related risk factors such as age, sex, body weight, medical history of cardiac disease and comorbidities [5]. However, some environmental factors are also reported to be related to the incidence of OHCA [6]. It has been reported that sudden cardiac arrest follows a chronological pattern [7-8]; for example, a seasonal variability was observed with a higher incidence of events noticed during winter [9]. Some studies have also revealed an association between atmospheric conditions and cardiac acute events in different geographical regions. There is a considerable evidence that extreme temperatures and sudden temperature changes increase acute cardiac events rate [10-14]. Presumably, not only the absolute temperatures are essential but day-to-day or month-to-month temperature changes could also have a potential significance. The other studies have found an association between atmospheric pressure and changes in arterial blood pressure 
or the incidence of acute coronary deaths [15-16]. To date, Polish experience is not well represented in this particular field. Poland lies in a moderate climate zone with mixed continental and oceanic influences and it evidently differs from other countries located not only in equatorial or subtropical climate, but also European ones. Recently we explored the monthly and seasonal variation of $\mathrm{OHCA}$ occurrence with respect to seasonal temperature and this is the first report among polish ones [17]. Potentially, advancing the knowledge about weather-related factors influencing OHCA occurrence in our climate may facilitate the development of management strategies aimed at improving the survival.

Therefore we aimed to investigate daily weather conditions and the incidence of OHCA of cardiac aetiology among the adult population of Opole district, Poland. In particular, we examined yet poorly explored individual atmospheric parameters that may possibly influence the incidence of OHCA, selecting the following: daily mean temperature, mean relative pressure, mean relative humidity, daily mean cloudiness, daily rainfall, daily snowfall, daily sunshine duration, storm occurrence, and day-to-day changes in mean temperature, mean relative pressure and mean relative humidity.

\section{Methods}

We performed a retrospective analysis of dispatch cards from Emergency Medical Services (EMS) in Opole (Poland) covering a 2-year period from January $1^{\text {st }}, 2006$ to December 31 $1^{\text {th }}, 2007$. Dispatch cards were compatible with the Utstein template. Cards without data regarding the study criteria were not considered for the analysis. Opole district is located on the south of Poland and occupies $1683 \mathrm{~km}^{2}$. During the study period, it was inhabited by approximately 262000 citizens (47.8\% of which were men). The district includes $129 \mathrm{~km}^{2}$ of urban areas inhabited by $56 \%$ of the population [18-19].

During the analysed period, there were 47549 ambulance departures, including 870 (1.83\%) departures due to OHCA. An OHCA was defined as an event with obvious cardiac arrest features that happened suddenly and unexpectedly and the mechanism of cardiac arrest was set based on the first recorded heart rhythm: shockable [ventricular fibrillation (VF) or tachycardia (VT)] or non-shockable [asystole or pulseless electrical activity (PEA)]. Patients with traumatic OHCA $(n=47)$ and under 18 years old $(n=7)$ were excluded from the analysis. Patients with late signs of death, defined by the presence of decomposition, rigor mortis or livor mortis were also excluded. A total of $815 \mathrm{OHCA}$ cases (406 subjects in 2006 and 409 in 2007) were selected for the study.

\section{Meteorological data}

Meteorological data were obtained from the database of the Institute of Meteorology and Water Management (Warsaw, Poland). The meteorological reports were available for each day and provided data regarding mean temperature, mean relative pressure, mean relative humidity, mean cloudiness, rainfall, snowfall, sunshine duration, and storm occurrence. For further analysis day-to-day changes in mean temperature, mean relative pressure, and mean relative humidity were calculated.

\section{Analysis of weather conditions and OHCA}

Temperature changes. The differences in OHCA occurrence were examined both between days with positive and negative temperatures and between 7 separate categories regarding the range of mean daily temperature $[1) \leq-5^{\circ} \mathrm{C}$; 2) $-4.9-0^{\circ} \mathrm{C}$; 3) $0.1-5^{\circ} \mathrm{C}$; 4) $5.1-10^{\circ} \mathrm{C}$; 5) $10.1-15^{\circ} \mathrm{C}$; 6) $15.1-20^{\circ} \mathrm{C}$; 7) > $20^{\circ} \mathrm{C}$. The $\mathrm{OHCA}$ occurrence was also investigated in relation to the increase or decrease of mean daily temperature between two consecutive days. Day-to-day temperature changes were divided into 6 categories (decrease over $4^{\circ} \mathrm{C}$, decrease between 3.9 and $2^{\circ} \mathrm{C}$, decrease between 1.9 and $0^{\circ} \mathrm{C}$, increase between 0.1 and $2^{\circ} \mathrm{C}$, increase between 2.1 and $4^{\circ} \mathrm{C}$, and increase over $4^{\circ} \mathrm{C}$ ).

Pressure changes. The pattern of OHCA occurrence regarding atmospheric pressure was explored among 9 categories [ $<980.0 \mathrm{hPa}$ and every $5 \mathrm{hPa}$ up to $>1015 \mathrm{hPa}$ ] and in relation to the drop or growth of the atmospheric pressure between two consecutive days. Day-to-day pressure changes were also divided into 4 categories (decrease of $5 \mathrm{hPa}$ or higher, decrease between 4.9 and $0 \mathrm{hPa}$, increase between 0.1 and $4.9 \mathrm{hPa}$, increase of $5 \mathrm{hPa}$ or higher).

Humidity changes. Days were divided into quartiles regarding mean daily humidity which revealed the following 4 categories: < 68.7\%, 68.7-79.7\%, $79.8-87.7 \%$ and $>87.7 \%$. Similarly to the abovementioned parameters the analysis of day-to-day humidity changes was performed. Firstly, the difference in $\mathrm{OHCA}$ occurrence between days with increase and decrease of humidity between two consecutive days was examined. Secondly, the analysis for 4 more specific categories was performed (decrease of $10 \%$ or higher, decrease between 9.9 and 5\%, decrease between 4.9 and $0 \%$, increase between 0.1 and $5 \%$, increase between 5.1 and $10 \%$, and increase higher than $10 \%$ ).

Other parameters. Both precipitation amount (in millimetres) and rainfall duration (in hours) were divided into three categories $(0.0 \mathrm{~mm}, 0.1$ to $5 \mathrm{~mm},>5 \mathrm{~mm}$ and $0.0 \mathrm{~h}, 0.1$ to $3 \mathrm{~h},>3 \mathrm{~h}$ respectively). The OHCA occurrence was also analysed regarding the incidence of 
Table 1. Characteristic of atmospheric conditions in the considered period

\begin{tabular}{lcc}
\hline \multicolumn{3}{l}{ Table 1. Atmospheric conditions } \\
\hline Parameter & Mean \pm SD & Range \\
\hline Temperature $\left({ }^{\circ} \mathrm{C}\right)$ & $9.77 \pm 8.51$ & -20.9 to 28.4 \\
Pressure $(\mathrm{hPa})$ & $997.101 \pm 8.34$ & 972.6 to 1027.2 \\
Humidity (\%) & $77.53 \pm 12.56$ & 39.4 to 100.0 \\
Rainfall (mm) & $1.49 \pm 3.57$ & 0.0 to 45.6 \\
Rainfall duration (h) & $1.86 \pm 3.399$ & 0.0 to 24.0 \\
Sunshine duration (h) & $5.28 \pm 4.59$ & 0.0 to 15.8 \\
Days with a fall $(\%)$ & & \\
Rainfall & 43 & \\
Snowfall & 11.9 & \\
Storm & 6.6 &
\end{tabular}

snowfall and storm. Sunshine and cloudiness duration during the day were presented in hours and grouped into 4 categories according to the quartile distribution.

\section{Statistical analysis}

The normality of the distribution was verified using the Shapiro-Wilk test. Continuous variables are presented as means \pm standard deviation and categorical variables as absolute frequencies and percentages. The comparison between two variables was performed with the Mann Whitney $U$ test or appropriate t-Student test according to the distribution. For comparison of more than two variables, Kruskal-Wallis test or ANOVA was used regarding the normality of data distribution. The analysis of groups divided by gender (males vs. females) and age ( $\leq 65$ years vs. $>65$ years) was made. The two-sided $p$-value $<0.05$ was considered significant. IBM SPSS Statistics version 23 was used to perform the analysis.

\section{Results}

\section{General characteristics}

General characteristics of the studied population and detailed epidemiology of OHCA have been recently published [17]. The majority of OHCA cases were men $(63 \%, p=0.0001)$ and people older than 65 years $(53.4 \%, p<0.001)$. Mean value of OHCA per day was $1.12 \pm 1.088$. Non-shockable rhythm (asystole, PEA) was diagnosed in $88.71 \%$ cases, whereas shockable rhythm (VF or VT) was present in $11.04 \%$ patients. Weather parameters are presented in Table 1.

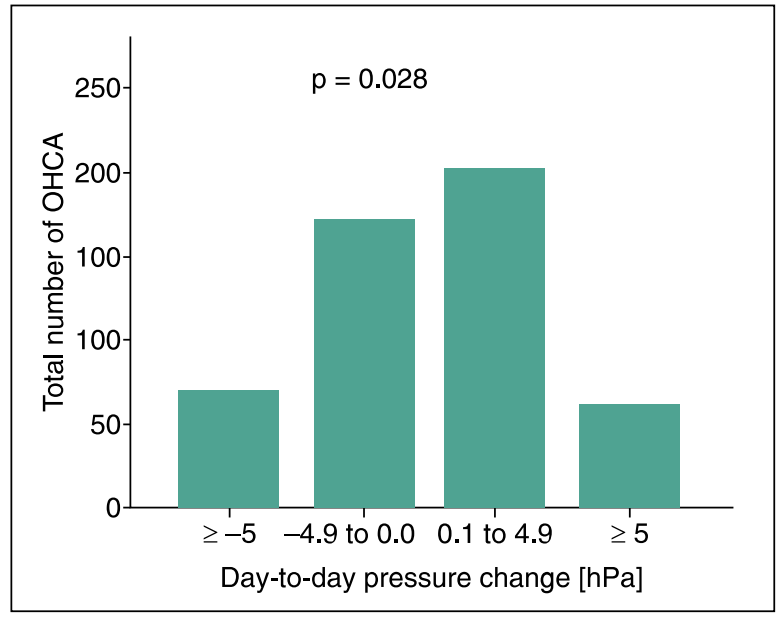

Figure 1. Distribution of OHCA cases in men group according to increase or decrease of day-to-day pressure change

Over the study period of 730 days the mean daily temperature was $9,7 \pm 8.51^{\circ} \mathrm{C}$, ranging from $-20.9^{\circ} \mathrm{C}$ to $28.4^{\circ} \mathrm{C}$. Negative temperatures were noticed on $13.7 \%$ of days. Comparison of mean daily temperatures between two consecutive days revealed a drop in $49.2 \%$, growth in $49.7 \%$, and no changes in $1.1 \%$ of days. Mean daily temperature decreased maximally by $18^{\circ} \mathrm{C}$ and increased by $11^{\circ} \mathrm{C}$ in comparison with the previous day. The atmospheric pressure varied from $972.6 \mathrm{hPa}$ to $1027.2 \mathrm{hPa}$ and the mean pressure value was $997.1 \pm 8.34 \mathrm{hPa}$. After the analysis of day-to-day atmospheric pressure changes, we observed that pressure decreased in $51 \%$ (maximal absolute decrease by $17.8 \mathrm{hPa}$ ) and increased in $43.5 \%$ (maximal absolute increase by $21.5 \mathrm{hPa}$ ) of cases. The mean humidity during the study period was $77.5 \pm 12.56 \%$, ranging from 39.4 to $100.0 \%$. The humidity decreased from day-to-day in $53.9 \%$ of cases and increased in $43.8 \%$. Maximal drop between two consecutive days was $32.6 \%$ while $35.2 \%$ accounted for maximal growth.

\section{Meteorological parameters and OHCA occurrence}

The analysis of the entire study population revealed none statistically significant differences in OHCA occurrence regarding all examined individual meteorological parameters. Nonetheless, we noticed the differences in OHCA occurrence with respect to atmospheric pressure changes in men and a population of $\leq 65$ years old. When male population is considered, higher OHCA incidence was observed when the day-to-day atmospheric pressure increased $(p=0.028$, Figure 1$)$. The division into 4 specific categories (Figure 2) also showed a statistically significant pattern $(p=0.037)$. A day with pressure decrease less than $5 \mathrm{hPa}$ presented the lowest median value of OHCA cases while the highest value 


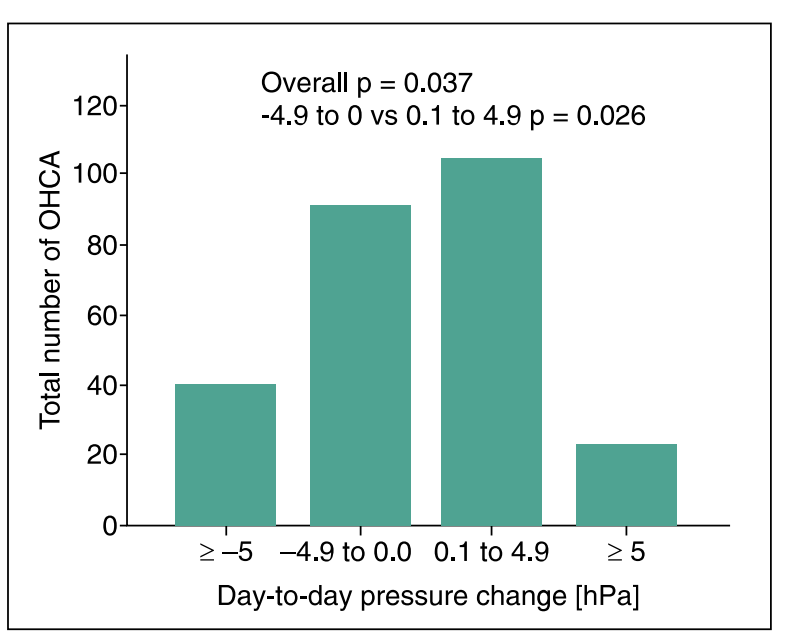

Figure 2. Distribution of OHCA occurrence in day-to-day pressure change groups in men group

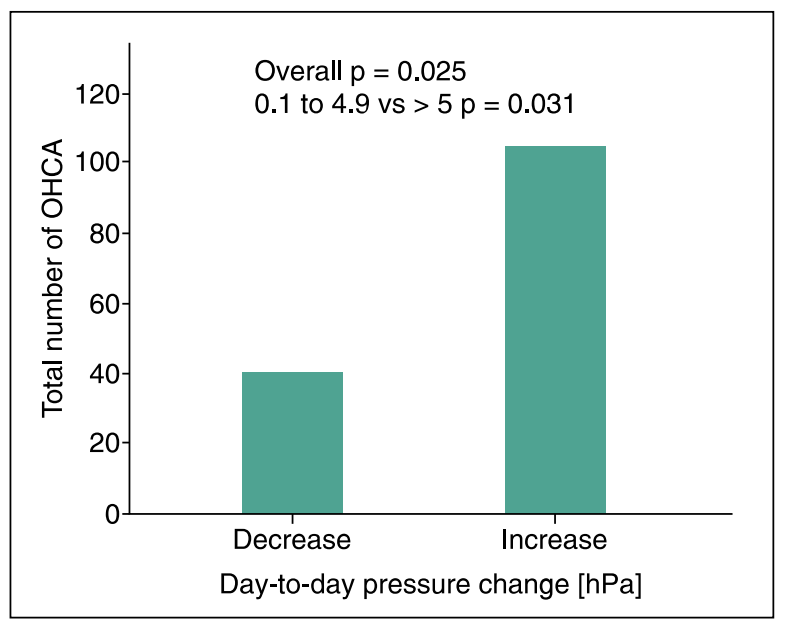

Figure 3. Distribution of OHCA occurrence in day-to-day pressure change groups in population $\leq 65$ years.

was observed in the group of pressure increase less than $5 \mathrm{hPa}(\mathrm{p}=0.026)$.

With regard to the population of $\leq 65$ years old, the division into 4 "day-to-day pressure changes" categories revealed significant differences $(p=0.025)$. Unlike in men group, the statistical significance was observed between days with pressure change up to $5 \mathrm{hPa}$ and days with the pressure increase more than $5 \mathrm{hPa}(\mathrm{p}=0.031)$ when more OHCA cases occurred on days with pressure change up to $5 \mathrm{hPa}$. Lower $\mathrm{OHCA}$ occurrence was observed in days with the pressure increase more than $5 \mathrm{hPa}$ in comparison to days with less intense atmospheric pressure increase $(p=0.031)$. The median and interquartile range distribution is presented in Figure 3. P-values almost reaching statistical significance were observed in this population for other meteorological parameters like positive/negative temperatures $(p=0.08)$, storm occurrence $(p=0.07)$ or absolute humidity $(p=0.07)$.

Similarly, we noted a tendency for OHCA to occur more often when the mean daily temperature increased between two consecutive days $(p=0.06)$.

\section{Discussion}

A substantial evidence of a temperature influence on cardiovascular events has been noted in studies from various countries, however, there are few studies that evaluated the associations between cardiac arrest and other multiple meteorological factors or their day-to-day change. This study is an attempt to describe various atmospheric conditions and the incidence of OHCA in the adult population of the southern region of Poland. According to the authors' knowledge, this study represents the first Polish experience in this field regarding so many various atmospheric parameters, so far.

The hypothesis of OHCA incidence being affected by temperature has been examined in studies across various countries. Extreme temperatures, both high and low have been identified to increase the risk of cardiovascular events. The authors'recently published study revealed a significantly higher incidence of $\mathrm{OHCA}$ in astronomical winter, which was the coldest season, in comparison to astronomical summer - the warmest one [17]. In terms of temperature-associated risk of $\mathrm{OHCA}$, previous reports evaluated also the relation between day-to-day temperature change and cardiovascular morbidity and mortality. The most recent study by Vicedo-Cabrera et al.[20] conducted in 6 European cities suggested that there was no relationship between interday temperature variations and mortality. On the contrary, Plavcová et al. reported that among the Czech population a significant increase in mortality was found after a large temperature rise and a decrease in mortality after a temperature drop [21]. Also in a study by Cheng et al. a temperature increase between consecutive days had a significant adverse impact on mortality [22]. It was also presented in a study by Guo et al. in which a significant change in temperature (particularly of more than $3^{\circ} \mathrm{C}$ ), whether positive or negative, resulted in an increased cardiovascular mortality rate [23]. On the other hand, in a study from 2016 Onozuka et al. evaluated 271698 OHCAs of presumed cardiac origin among Japanese population and reported that day-today change in temperature was not associated with OHCA [24]. Also, the results of this study consistently indicated no significant differences. Despite a tendency to a higher incidence of OHCA on days with a temperature rise, particularly of more than $4^{\circ} \mathrm{C}$, these results did not achieve any significance. 
The consequences of atmospheric pressure on cardiovascular morbidity and mortality have been studied less frequently and found contraindicating results. In terms of acute coronary syndromes (ACS), some did not find any relation between atmospheric pressure and the incidence of ACS [25-26] whereas others did. The MONICA Project, a large cohort study reported a V-shaped association between pressure and the incidence of coronary events [16]. In this study, both increases and decreases in atmospheric pressure were associated with an increase of daily coronary event rates. Wang et al. presented that the highest daily ACS events rate were observed on days with low pressure [27]. Another study by Houck et al. reported there was a significant correlation between a decrease in atmospheric pressure and the occurrence of ACS the day after a pressure decrease [28]. On the other hand, in a study among Swiss population Goerre et al. described a positive correlation between pressure and ACS [29]. In terms of OHCA pressure-dependence, a number of studies is even more limited. In a study among Japanese population, Tanigawa-Sugihara et al. reported a positive relationship between atmospheric pressure and OHCA incidence [30].

Among these inconsistent results, this study also showed no significant difference in OHCA occurrence with regard to average atmospheric pressure. Nonetheless, significant differences were noticed for day-to-day atmospheric pressure change and OHCA incidence. In a group of men and in a population of $\leq 65$ years a pressure rise between consecutive days resulted in a higher incidence of OHCA. These results are in opposition to those in the aforementioned study by Tanigawa-Sugihara et al. in which an increase in the difference of pressure from the previous day was associated with a decrease in OHCA events in elderly [30]. However, their study did not include gender separation and the population classified as elderly was of $\geq 75$ years. This inconsistency among studies possibly results from undefined adverse influence of atmospheric pressure on the cardiovascular system. To establish a cause-and-effect relationship more data are needed on the interaction between the pathophysiological mechanisms of the cardiac arrest and barometric pressure variations.

This study has several limitations. Retrospective and observational nature of this study are one of the main limitations. Another one is the difficulty in the assessment of the precise time of event occurrence mainly due to the adopted methodology. The authors obtained daily meteorological data and merged them with the OHCA data, they did not know the exact weather conditions at the moment of cardiac arrest. It is also possible that meteorological parameters and their day-to-day change might have long-lasting delayed effectswhat is very difficult to assess. In addition, it was not possible to analyse the combinations of atmospheric conditions. This study is also limited by the fact that Opole district is a relatively small territory and might be insufficiently representative in terms of described phenomena. Thus, although the authors of this study consider their data valuable, it still should be taken with caution and require both the amplification and confirmation in larger-scaled studies.

\section{Conclusions}

This preliminary analysis has shown that among many weather parameters, only a few of them might be significant for the occurrence of OHCA. It seems that in a moderate climate of Poland only the atmospheric pressure changes may have the potential to affect OHCA. More studies are needed to describe these interesting but still poorly understood phenomena. Although modest, the results of this work complement Polish experience in this particular setting.

Funding: This research did not receive any specific grant from funding agencies in the public, commercial, or not-for-profit sectors.

Disclosure of interest: The authors report no conflicts of interest.

\section{References}

1. Nichol G, Rumsfeld J, Eigel B, et al. American Heart Association Emergency Cardiovascular Care Committee, American Heart Association Council on Cardiopulmonary, Perioperative, and Critical Care, American Heart Association Council on Cardiovascular Nursing, American Heart Association Council on Clinical Cardiology, Quality of Care and Outcomes Research Interdisciplinary Working Group. Essential features of designating out-of-hospital cardiac arrest as a reportable event: a scientific statement from the American Heart Association Emergency Cardiovascular Care Committee; Council on Cardiopulmonary, Perioperative, and Critical Care; Council on Cardiovascular Nursing; Council on Clinical Cardiology; and Quality of Care and Outcomes Research Interdisciplinary Working Group. Circulation. 2008; 117(17): 2299-2308, doi: 10.1161/CIRCULATIONAHA.107.189472, indexed in Pubmed: 18413503.

2. Iwami T, Nichol G. Hiraide A, et al. Continuous improvements in "chain of survival" increased survival after out-of-hospital cardiac arrests: a large-scale population-based study. Circulation. 2009; 119(5): 728-734, doi: 10.1161/CIRCULATIONAHA.108.802058, indexed in Pubmed: 19171854

3. Atwood C, Eisenberg MS, Herlitz J, et al. Incidence of EMS-treated out-of-hospital cardiac arrest in Europe. Resuscitation. 2005; 67(1): 75-80, doi: 10.1016/j.resuscitation.2005.03.021, indexed in Pubmed: 16199289.

4. McNally B, Robb R, Mehta M, et al. Centers for Disease Control and Prevention. Out-of-hospital cardiac arrest surveillance: Cardiac Arrest Registry to Enhance Survival (CARES), United States, October 1, 2005, December 31, 2010. MMWR Surveill Summ. 2011; 60(8): 1-19, indexed in Pubmed: 21796098.

5. Roger VL, Go AS, Lloyd-Jones DM, et al. American Heart Association Statistics Committee and Stroke Statistics Subcommittee. Heart disease and stroke statistics-2011 update: a report from the American Heart Association. Circulation. 2011; 123(4): e18-e209, doi: 10.1161/CIR.0b013e3182009701, indexed in Pubmed: 21160056.

6. Paradis NA, Halperin HR, Kern MB, et al. Cardiac arrest: The science and practice of resuscitation medicine, 2nd edn. UK: Cambridge University Press.; 2007 
7. Hayashi S, Toyoshima H, Tanabe N, et al. Daily peaks in the incidence of sudden cardiac death and fatal stroke in Niigata Prefecture. Jpn Circ J. 1996; 60(4): 193-200, indexed in Pubmed: 8726167.

8. Herlitz J, Eek M, Holmberg M, et al. Diurnal, weekly and seasonal rhythm of out of hospital cardiac arrest in Sweden. Resuscitation. 2002; 54(2): 133-138, indexed in Pubmed: 12161292.

9. Arntz HR, Willich SN, Schreiber C, et al. Diurnal, weekly and seasonal variation of sudden death. Population-based analysis of 24,061 consecutive cases. Eur Heart J. 2000; 21(4): 315-320, doi: 10.1053/euhj.1999.1739, indexed in Pubmed: 10653679.

10. Seretakis D, Lagiou $P$, Lipworth $L$, et al. Changing seasonality of mortality from coronary heart disease. JAMA. 1997; 278(12): 1012-1014 indexed in Pubmed: 9307350

11. Lin S, Luo M, Walker RJ, et al. Extreme high temperatures and hospital admissions for respiratory and cardiovascular diseases. Epidemiology 2009; 20(5): 738-746, doi: 10.1097/EDE.0b013e3181ad5522, indexed in Pubmed: 19593155.

12. Michelozzi P, Accetta G, De Sario M, et al. PHEWE Collaborative Group. High temperature and hospitalizations for cardiovascular and respiratory causes in 12 European cities. Am J Respir Crit Care Med. 2009; 179(5): 383-389, doi: 10.1164/rccm.200802-2170C, indexed in Pubmed: 19060232

13. Gronlund CJ, Zanobetti A, Schwartz JD, et al. Heat, heat waves, and hospital admissions among the elderly in the United States, 1992-2006. Environ Health Perspect. 2014; 122(11): 1187-1192, doi 10.1289/ehp.1206132, indexed in Pubmed: 24905551.

14. Chen R, Li T, Cai J, et al. Extreme temperatures and out-of-hospital coronary deaths in six large Chinese cities. J Epidemiol Community Health. 2014; 68(12): 1119-1124, doi: 10.1136/jech-2014-204012, indexed in Pubmed: 25108018.

15. Weinbacher M, Martina B, Bart T, et al. Blood pressure and atmospheric pressure. Ann N Y Acad Sci. 1996; 783: 335-336, indexed in Pubmed: 8853662

16. Danet S, Richard F, Montaye M, et al. Unhealthy effects of atmospheric temperature and pressure on the occurrence of myocardial infarction and coronary deaths. A 10-year survey: the Lille-World Health Organization MONICA project (Monitoring trends and determinants in cardiovascular disease). Circulation. 1999; 100(1): E1-E7, indexed in Pubmed: 10393689.

17. Szczerbinski S, Ratajczak J, Lach P, et al. Epidemiology and chronobiology of out-of-hospital cardiac arrest in a subpopulation of southern Poland: A two-year observation. Cardiol J. 2018 [Epub ahead of print] doi: 10.5603/CJ.a2018.0025, indexed in Pubmed: 29611174

18. Boczar D, Molodowicz M, et al. Ludność, ruch naturalny i migracje w województwie opolskim w 2006r. [Poulation, vital statistics and migration of population in opolskie voivodshi in 2006]. Urzad Statystyczny we Wrocławiu Wydział Poligrafii w Legnicy; 2007. p 7-20.
19. Molodowicz M, et al. Ludność, ruch naturalny i migracje w województwie opolskim w 2007r. [Poulation, vital statistics and migration of population in opolskie voivodshi in 2007]. Urząd Statystyczny we Wrocławiu, Wydział Poligrafii w Legnicy; 2008. p 7-22.

20. Vicedo-Cabrera AM, Forsberg B, Tobias A, et al. Associations of Inter- and Intraday Temperature Change With Mortality. Am J Epidemiol. 2016; 183(4): 286-293, doi: 10.1093/aje/kwv205, indexed in Pubmed: 26811244

21. Plavcová E, Kyselý J. Relationships between sudden weather changes in summer and mortality in the Czech Republic, 1986-2005. Int J Biometeorol. 2010; 54(5): 539-551, doi: 10.1007/s00484-010-0303-7, indexed in Pubmed: 20169367.

22. Cheng J, Zhu R, Xu Z, et al. Temperature variation between neighboring days and mortality: a distributed lag non-linear analysis. Int J Public Health. 2014; 59(6): 923-931, doi: 10.1007/s00038-014-0611-5, indexed in Pubmed: 25280527.

23. Guo Y, Barnett AG, Yu W, et al. A large change in temperature between neighbouring days increases the risk of mortality. PLoS One. 2011; 6(2): e16511, doi: 10.1371/journal.pone.0016511, indexed in Pubmed: 21311772

24. Onozuka D, Hagihara A. Associations of day-to-day temperature change and diurnal temperature range with out-of-hospital cardiac arrest. Eur J Prev Cardiol. 2017; 24(2): 204-212, doi: 10.1177/2047487316674818, indexed in Pubmed: 27798364

25. Abrignani MG, Corrao S, Biondo GB, et al. Influence of climatic variables on acute myocardial infarction hospital admissions. Int J Cardiol. 2009; 137(2): 123-129, doi: 10.1016/j.ijcard.2008.06.036, indexed in Pubmed: 18694607

26. Verberkmoes NJ, Soliman Hamad MA, Ter Woorst JF, et al. Impact of temperature and atmospheric pressure on the incidence of major acute cardiovascular events. Neth Heart J. 2012; 20(5): 193-196, doi: 10.1007/s12471-012-0258-x, indexed in Pubmed: 22328355

27. Wang $\mathrm{H}$, Matsumura $\mathrm{M}$, Kakehashi $\mathrm{M}$, et al. Effects of atmospheric temperature and pressure on the occurrence of acute myocardial infarction in Hiroshima City, Japan. Hiroshima J Med Sci. 2006; 55(2): 45-51, indexed in Pubmed: 16813068.

28. Houck PD, Lethen JF, Riggs MW et al Relation of atmospheric pressure changes and the occurrences of acute myocardial infarction and stroke. Am J Cardiol. 2005; 96(1): 45-51, doi: 10.1016/j. amjcard.2005.02.042, indexed in Pubmed: 15979431.

29. Goerre S, Egli C, Gerber S, et al. Impact of weather and climate on the incidence of acute coronary syndromes. Int J Cardiol. 2007; 118(1): 3640, doi: 10.1016/j.jicard.2006.06.015, indexed in Pubmed: 16904213.

30. Tanigawa-Sugihara K, Iwami T, Nishiyama C, et al. Association Between Atmospheric Conditions and Occurrence of Out-of-Hospital Cardiac Arrest. Circulation Journal. 2013; 77(8): 2073-2078, doi: 10.1253/circj. cj-13-0076. 